\title{
Yield Variability as Influenced by Climate: A Statistical Investigation
}

\author{
Chi-Chung Chen \\ Assistant Professor \\ Dept. of Agricultural Economics \\ National Chung-Hsing University \\ Taichung, Taiwan \\ Bruce A. McCarl \\ Professor \\ Department of Agricultural Economics \\ Texas A\&M University \\ College Station, TX. \\ mccarl@tamu.edu \\ (409) 845-1706 \\ David E. Schimmelpfennig \\ Program Leader \\ Economic Research Service \\ United States Department of Agriculture \\ Washington D.C. \\ des@econ.ag.gov \\ (202) 694-5507
}

Seniority of authorship is shared. This research was partially supported by and is a contribution to the National Assessment of Climate Change, Agricultural Focus Group, supported by the U.S. Global Climate Change Office. The authors thank John Reilly for useful discussions. The views expressed are not necessarily those of the U.S. Department of Agriculture. 


\title{
Yield Variability as Influenced by Climate: A Statistical Investigation
}

\author{
Abstract: \\ Studies of agricultural impacts of possible future climate change seldom report distributions of \\ potential outcomes. Part of the reason for this may be that little empirical evidence is available on \\ sources of agricultural output variability. This study presents maximum likelihood panel data estimates \\ of the impacts of climate on yield variability for the major U.S. agricultural crops. Panel data time- \\ series techniques are used to specify and estimate a stochastic production function of the form \\ suggested by Just and Pope. The effects of climate on yield levels and variances are shown to vary \\ depending on the crop. For sorghum more rainfall and higher temperatures increase yields while \\ increasing yield variability. Precipitation and temperature individually have opposite effects on corn \\ yield levels and variability.
}

Key words: Climate, yield variability, time-series, panel data Just-Pope 


\section{Yield Variability as Influenced by Climate: A Statistical Investigation}

Variability of agricultural yield is well known to depend on the weather. Extreme weather events like hurricanes and droughts have obvious impacts and recently necessitated two disaster relief bills for farmers. Identification and prediction of the influences of seasonal-to-interannual climate phenomena, like the El Nii o Southern Oscillation (ENSO), has brought attention to possible short-term impacts of changes in climate. More subtle seasonal phenomena also have been linked to agricultural productivity, with Florida citrus freeze risk (Downton and Miller), and dryland maize production in southern Africa having been shown to be influenced by ENSO and other ocean circulation patterns (Cane, Eshel, and Buckland).

The considerable attention that has been focused on agricultural impacts of climate change, has largely focused on fifty to 100 year mean climate change effects (Lewandrowski and Schimmelpfennig; Adams et al.). Climate variability has been considered in a few longer term studies, but the studies do not generally incorporate sensitivity tests or estimate changes in distributions of outcomes (Mearns, Rosenzweig, and Goldberg, 1996 and 1997; Schimmelpfennig).

Factors other than climate influence the variability of agricultural production. Anderson and Hazell argue that adoption of common high-yielding varieties, uniform planting practices, and common timing of field operations, have caused yields of many crops to become more sensitive to the weather, especially in developing countries. Hazell makes similar observations concerning cereal production in the United States. Roumasset et al. and Tollini and Seagraves argue that increased fertilizer use has had an impact.

An open question is how sensitive might agricultural yield variability be to climatic change? The 
ultimate answer will depend upon future technological progress, crop climatic adaptation, and $\mathrm{CO}_{2}$ fertilization effects among many other factors, but a current statistical answer can be obtained from historical records relating crop yield variability to climate. An approach using pooled time-series crosssectional data much like that employed in Mendelsohn, Nordhaus and Shaw can be used to measure yield variability impacts of shifts in climate. The question addressed is how is the variability of U.S. corn, cotton, sorghum, soybeans, and wheat yields affected by shifts in climate?

\section{Methodological Background}

Just and Pope $(1978,1979)$ developed a stochastic production function specification that after estimation explicitly shows the effects of independent variables on the probability distribution of output (p.79) and does not impose dependence between an item's effect on yield variability and it's effect on mean yield. Just and Pope $(1978,1979)$ described both Maximum Likelihood (MLE) and a three step, feasible generalized least squares (FGLS) procedure for estimating the function.

Antle extended Just and Pope's approach by developing a moment-based stochastic production function that estimated higher order moments and used it in the estimation of a set of input demand functions and a distribution of risk preferences. Love and Buccola applied related techniques to primal risk models, allowing joint estimation of either technology and yield variability or input demands and yield variability. Saha, Shumway, and Talpaz's showed how to jointly estimate risk preferences and the production technology. Buccola and McCarl investigated the small-sample properties of Just and Pope's three stage method, using Monte Carlo experiments. $\quad$ McCarl and Rettig used the three step approach to examine the effects of changes in ocean conditions on the variability of the salmon catch. 
Despite the fact that Just-Pope production functions have traditionally been estimated by the three-step FGLS approach, Saha, Havenner, and Talpaz show in Monte Carlo experiments that for small samples, MLEs are more efficient and unbiased than FGLS estimates. They show that FGLS estimates systematically understate the risk effects of inputs, a serious problem in the present context.

\section{Panel Data Set for Estimation}

The availability of state level detailed climate and yield data across the U.S. allows for the exploration of both inter-temporal and inter-spatial variances in the data with state level characteristics, and changes in technology controlled. State level yields and acreage harvested for 25 years, 1973 to

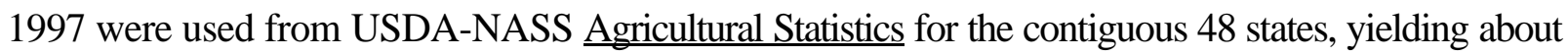
1200 observations.

State-level climate data that matches the agricultural output data is available on the NOAA Internet home-page which includes time series observations for thousands of weather stations. The temperature data predominantly April to November averages for the published weather stations in a state. For regions growing predominantly winter wheat, we used the November to March average temperature. The rainfall data are state annual totals, reflecting both precipitation falling directly on a crop, and also inter-seasonal water accumulation.

\section{Time Series Estimation}

The Just-Pope production function can be estimated from panel data relating yield to exogenous variables. This procedure produces estimates of the impacts of the exogenous variables on levels and the variance of yield. An assumption of the model is that included variables are stationary. Deterministic and stochastic trends in variables can introduce spurious correlations between the variables, because 
the errors in the data-generating-processes for different series might not be independent (Granger and Newbold). In other words, correlations might be detected between variables that are increasing for different reasons and in increments that are uncorrelated (Banerjee, et al, p.71).

An early method for accounting for the trends in many economic time series, and the positive trends that are certainly evident in agricultural yields, was to include a deterministic time trend. Unfortunately, correlations between variables may still be spurious even when deterministic time trends are accounted for. To make matters worse, standard t-statistics on the time trend variable are inflated when the other variables in a regression are non-stationary (Phillips). This might make it seem that a time trend is properly accounted for when it is not. The solution to these problems, is to first test for stationarity. Non-stationary variables can be differenced once and retested. If the differenced versions are stationary, the variables are said to be integrated order one or I(1). Stationary time series are integrated order zero or I(0). Regressions on stationary variables may satisfy ideal conditions, and inferences on a deterministic time trend can be made safely. Even though our data has more regions than annual observations, any data set with a time dimension of 20 years or more should be tested for its time series properties.

Practitioners have tested for unit roots and used differencing or other filtering techniques to make their variables stationary. Until recently the time-series characteristics of panel data have been difficult to characterize. The observations on one or more regions in a panel could be non-stationary when considered alone, but with panel data models all of the regions are generally taken together. The question has been how to characterize the time series properties of one variable made up of many regions? New tests are available that offer more power than earlier tests on region series. These new 
tests for stationarity are applied to each variable taking the whole panel at once. This avoids possibly conflicting time series information on regions in the panel. There are several versions of these so-called panel unit root tests due to Im, Pesaran, and Shin, Levin and Lin (1992, 1993), and Quah. Quah's test does not allow for region specific effects. Since we show the importance of region effects in the next section, we rely on Im et al.'s test. Their test shows better finite sample performance than the tests due to Levin and Lin, in Monte Carlo simulations on panels with a large number of regions relative to the number of time periods. ${ }^{1}$

\section{Panel Unit Root Tests}

Im, Pesaran, and Shin propose a series of unit root test statistics in dynamic heterogenous panels based on individual Dickey-Fuller (Dickey and Fuller) regressions. The LM-bar test is based on the mean of individual unit root statistics. The test is valid when the errors in the region regressions are serially uncorrelated, and normally and independently distributed across regions. Under these circumstances LM-bar is distributed as standard normal as long as the number of regions $(\mathrm{N})$ is large relative to the number of time periods (T). For wheat, corn, and soybeans we have 25 annual observations with in some cases substate level observations. There are, e.g. 1400 observations for wheat, with 25 years of data across 56 regions. This is the widest panel, but for all the crops considered here, $\mathrm{N}$ is large relative to $\mathrm{T}$.

Suppose that the variable of interest, $\mathrm{y}_{\mathrm{it}}$, has a representation as a stochastic first-order autoregressive process for region $\mathrm{i}$ and time period $\mathrm{t}$,

\footnotetext{
${ }^{1}$ Application of the Im, Pesaran, and Shin test to another data set can be found in Coakley and Fuertes. Heimonen uses Levin and Lin's test.
} 


$$
\Delta y_{i t}=\alpha_{i}+\beta_{i} y_{i, t-1}+\varepsilon_{i t}, \quad i=1, \ldots, N ; t=1, \ldots, T,
$$

where $\Delta y_{i t}=y_{i t}-y_{i, t-1}$. The null hypothesis of a unit root in (1) is then a test of

$$
H_{0}: \beta_{i}=0 \text { for all } i
$$

Under the assumption of serially uncorrelated errors, the LM-bar statistic used

to test this null hypothesis is defined by

$$
\Gamma_{L M}=\frac{\sqrt{N}\left\{L \bar{M}_{N T}-E\left(\eta_{T}\right)\right\}}{\sqrt{\operatorname{Var}\left(\eta_{T}\right)}} .
$$

LM-bar is the simple average of $\mathrm{N}$ region Lagrange Multipliers taken from equation (1), and is a standard normal variate calculated as follows

$$
L \bar{M}_{N T}=\frac{1}{N} \sum_{i=1}^{N} L M_{i T} \quad, \quad L M_{i t}=\frac{T \Delta y_{i}^{\prime} P_{i} \Delta y_{i}}{\Delta y_{i}^{\prime} M_{t} \Delta y_{i}}
$$

where $\mathrm{J}_{\mathrm{T}}$ is a $\mathrm{Tx} 1$ vector of ones, and

$$
\begin{aligned}
& M_{\tau}=I_{T}-\tau_{T}\left(\tau_{T}^{\prime} \tau_{T}\right)^{-1} \tau_{T}^{\prime}, \\
& P_{i}=M_{\tau} y_{i,-1}\left(y_{i,-1}^{\prime} M_{\tau} y_{i,-1}\right)^{-1} y_{i,-1}^{\prime} M_{\tau}, \\
& y_{i,-1}=\left(y_{i 0,} y_{i 1}, \ldots, y_{i, T-1}\right)^{\prime}, \text { and } \Delta y_{i}=\left(\Delta y_{i 1}, \Delta y_{i 2}, \ldots, \Delta y_{i T}\right)^{\prime}
\end{aligned}
$$

To determine the mean and variance of $\eta_{i T}, \mathrm{i}=1,2, \ldots, \mathrm{N}$, it is necessary to first calculate

$$
\eta_{i t}=\frac{T\left(v_{i}^{\prime} M_{\tau} H L v_{i}\right)^{2}}{\left(v_{i}^{\prime} L^{\prime} H^{\prime} M_{\tau} H L v_{i}\right)\left(v_{i}^{\prime} M_{\tau} v_{i}\right)}, v_{i}=\frac{\varepsilon_{i}}{\sigma_{i}} \sim N\left(0, I_{T}\right) .
$$


where

$$
\underset{T \times T}{H}=\left[\begin{array}{ccccc}
1 & 0 & 0 & \ldots & 0 \\
1 & 1 & 0 & \ldots & 0 \\
1 & 1 & 1 & \ldots & 0 \\
& & & \ldots & \\
1 & 1 & 1 & \ldots & 1
\end{array}\right] \underset{T \times T}{L}=\left[\begin{array}{cccccc}
0 & 0 & 0 & \ldots & 0 & 0 \\
1 & 0 & 0 & \ldots & 0 & 0 \\
0 & 1 & 0 & \ldots & 0 & 0 \\
& & & \ldots & & 0 \\
0 & 0 & 0 & \ldots & 1 & 0
\end{array}\right]
$$

When the assumptions hold, $\mathrm{O}_{\mathrm{iT}}$ will be identically and independently distributed with a finite mean, $E\left(\eta_{i T}\right)$, and finite variance, $\operatorname{Var}\left(\eta_{i T}\right)$, for any $\mathrm{T}<\mathrm{N} .^{2}$

\section{Results of the Panel Unit Root Test}

The above panel unit root test procedure is individually applied to each of our potential dependent (yield) and independent variables (acreage, rainfall, and temperature). The results in Table 1 show that for corn, cotton, sorghum, soybeans, and wheat, the variables are stationary as a panel or integrated order zero $(\mathrm{I}(0))$, rejecting the null hypothesis of a unit root. To test the sensitivity of this result to possible violation of the assumption of serially uncorrelated errors, either the error terms can be tested directly, or an additional test can be performed.

A slightly modified test is described in Im, Pesaran, and Shin that is robust to serial correlation. Since the results we obtain by this second method are the same as for the first, reported in the second section of Table 1, we conclude that we do not have serial correlation in the errors of any of the variables. The bottom section of Table 1, shows that a different modification of the test, based on demeaned variables in each panel, yields slightly different results. Since the de-meaned version of the test

\footnotetext{
${ }^{2} \mathrm{~A}$ Shazam program that implements the procedure in this sub-section is available from the authors upon request.
} 
is robust to correlation across regions, we conclude that there is correlation across regions. This result is not surprising since we will show the existence of random region effects in the production functions that we estimate in the next section. We proceed by differencing the non-stationary variables, sorghum yield, cotton precipitation, and soybean temperature, in their region panels. These differenced versions are re-tested as panels and are shown to be stationary or $\mathrm{I}(0)$.

These panel time series characteristics of the data are used in formulating the estimation approach. Stationary versions of all of the variables are used in the panel production function model in the next section. This avoids possible spurious correlations between variables and allows the establishment of valid relationships. In addition, a deterministic time trend may be included that does not suffer from an inflated t-statistic.

\section{Fixed or Random Effects?}

Having established the time series properties of the variables, it is important to establish the correct panel model form. Results of the previous section reveal that some of the variables in Table 1 have correlations across regions. To test for fixed or random region effects in the model, several approaches are available.

The Breusch and Pagan test considers a null hypothesis that the variance of region and time specific effects is zero, in a two-way error component model. Honda suggests a one-sided version of this test, which is preferred because of expected non-negative variance components. Honda's version of the test is a uniformly most powerful test of $\mathrm{H}_{0}:{ }_{\mu}^{2}=0$ vs. fixed effects, where $\mu$ are unobserved region specific effects. The test statistic is (Baltagi p.62), 
(2) $H O=\sqrt{\frac{N T}{2(T-1)}}\left[\frac{\tilde{u^{\prime}}\left(I_{N} \otimes J_{T}\right) \tilde{u}}{\tilde{u^{\prime} \tilde{u}}}-1\right] \stackrel{H_{0}}{\rightarrow} N(0,1)$

where $\mathrm{N}$ are the number of cross-sections (regions);

$\mathrm{T}$ the number of time-series observations;

$\sim$

$u$ is a vector of residuals;

$I_{N}$ is an identity matrix with dimension $\mathrm{N}$;

$J_{T}$ is a matrix of ones with dimension T;

$$
\mathrm{u}_{\mathrm{i}} \sim \operatorname{IID}\left(\mathrm{O}, \sigma_{\mathrm{u}}^{2}\right), \quad \mathrm{v}_{\mathrm{it}} \sim \operatorname{III}\left(\mathrm{O}, \sigma_{\mathrm{v}}^{2}\right)
$$

The results from the estimation of (2), in the second row of Table 2, indicates that the null hypothesis (HO) is rejected for all five equations, and a zero variance on the region effect is rejected with $99 \%$ confidence. An alternative test for fixed or random region effects is provided by Hausman.

\section{The MLE Approach to Estimating the Production Function}

The previous sections established stationarity of the variables and random region effects, without ruling out possible deterministic trends. Following Saha, Havenner and Talpaz we estimate production functions of the form

$$
\text { (3) } y=f(X, \beta)+h(X, \alpha) \varepsilon
$$

where y is crop yield (corn, cotton, sorghum, soybeans, and wheat), $\mathrm{f}$ (@is an average production function, and $\mathrm{X}$ is a set of independent explanatory variables (climate, location, and time period). The functional form $\mathrm{h}$ @for the error term $\mathrm{u}_{\mathrm{i}}$, is an explicit form for heteroskedastic errors, allowing 
estimation of variance effects. Estimates of the parameters of $\mathrm{f}$ @give the average effect of the independent variables on yield, while $\mathrm{h}^{2}$ (@gives the effect of each independent variable on the variance of yield. The interpretation of the signs on the parameters of $h$ (Quare straightforward. If the marginal effect on yield variance of any independent variable is positive, then increases in that variable increase the standard deviation of yield, while a negative sign implies increases in that variable reduces yield variance.

The log-likelihood function is then:

$$
\text { (4) } \ln \mathrm{L}=-\frac{1}{2}\left[\mathrm{n} * \ln (2 \pi)+\sum_{\mathrm{i}=1}^{\mathrm{n}} \ln \left(\mathrm{h}\left(\mathrm{X}_{\mathrm{i}}, \alpha\right)^{2}\right)+\sum_{\mathrm{i}=1}^{\mathrm{n}} \frac{\left(\mathrm{y}_{\mathrm{i}}-\mathrm{f}\left(\mathrm{X}_{\mathrm{i}}, \beta\right)\right)^{2}}{\mathrm{~h}\left(\mathrm{X}_{\mathrm{i}}, \alpha\right)^{2}}\right] \text {. }
$$

Due to advances in non-linear optimization procedures, the parameters $\alpha$ and $\beta$ can be estimated in single-stage maximization of (4), under the assumptions that $y_{i} \sim N\left(f\left(X_{i}, \beta\right), h\left(X_{i}, \alpha\right)^{2}\right)$ and $\varepsilon_{i} \sim N(0,1)$

\section{Crop Yield Production Function Estimates}

After controlling for random effects, the MLEs of the $\mathrm{f}(\mathrm{X}, \$)$ part of the crop production functions are displayed in Table 3. Two specifications are tested, linear and Cobb-Douglas, and for precipitation and temperature for corn, cotton and sorghum these forms give similar results. The sign on precipitation is positive for all three crops and is negative on temperature. This indicates that crop yields increase with more rainfall and decrease with higher temperatures, holding acreage constant and after controlling for a deterministic time trend that may serve as a proxy for the non-stochastic portion 
of the advance of agricultural technology.

Higher temperatures positively impact soybean yields (Cobb-Douglas estimate insignificant) and negatively impact wheat yields. The coefficients on the deterministic time trend are positive and significant as expected for all crops, except the Cobb-Douglas estimates for cotton and wheat. This may come from the tendency of Cobb-Douglas forms to pick up curvature because this form is nonlinear over a wide range of parameter values, and may indicate a declining rate of increase in the effect of technology on yield rather than an actual negative impact of technology .

The coefficients for rainfall and temperature can be converted to elasticities by multiplying by sample average climate and dividing by average yield. These elasticities are reported in Table 4 . For corn yields, the percentage effects of changes in climate estimated by Cobb-Douglas are higher than the linear estimates. Elasticities for the other crops are mixed, with uniformly high elasticities being measured for both rainfall and temperature on sorghum.

\section{A Test of Model Adequacy}

Before considering variability estimates in the next section, it is worthwhile to test the adequacy of the panel production function models. The classical assumption of the random effects model is that the errors are region specific. The significance of a deterministic time trend along with the other stationary variables, raises a question whether region production function errors might also be time specific. If serial correlation was previously ignored, estimates in Table 3 could be consistent but inefficient, with biased standard errors.

Since random region effects are identified in Table 2, it is appropriate to test for serial correlation jointly with this information. Baltagi and Li present a series of tests for serial correlation that 
are carried out jointly with various assumptions concerning region effects. Their Lagrange Multiplier (LM) test for zero first-order serial correlation assuming random region effects, is the same whether the alternative is $\mathrm{AR}(1)$ or $\mathrm{MA}(1)$ (Baltagi, pp.91-93), which is fortunate as we have no way of testing which is the appropriate alternative.

For AR(1) serial correlation, a new specification of the error terms in equation (4) are as an $\operatorname{AR}(1)$ process with $v_{i t}=\rho v_{i, t-1}+\varepsilon_{i t}, \quad \varepsilon_{i t} \sim N\left(0, \sigma_{\varepsilon}^{2}\right)$. The null hypothesis is the restriction on this equation that $H_{0}: \rho=0$. The test statistic $L M=\left(\hat{D}_{\rho}\right)^{2} \hat{J}^{11}$ is distributed $x_{1}^{2}$ for large $\mathrm{N}$, where

$$
\begin{aligned}
& \hat{D}_{\rho}=[N(T-1) / T] \frac{\hat{\sigma}_{1}-\hat{\sigma}_{\varepsilon}}{\wedge 2}+\left(\hat{\sigma}_{\varepsilon}^{2} / 2\right) \hat{u^{\prime}}\left\{I_{N} \otimes\left[\left(\frac{\bar{J}_{T}}{\wedge 2}+\frac{E_{T}}{\wedge 2}\right) G\left(\frac{\bar{J}_{T}}{\wedge 2}+\frac{E_{T}}{\wedge 2}\right)\right]\right\} \hat{u} \\
& \begin{array}{lllll}
\sigma_{1} & \sigma_{1} & \sigma_{\varepsilon} & \sigma_{1} & \sigma_{\varepsilon}
\end{array} \\
& \hat{J}^{11}=N^{2} T^{2}(T-1) / \operatorname{det}(\hat{J}) 4 \hat{\sigma}_{1}^{4} \hat{\sigma}_{\varepsilon}
\end{aligned}
$$

$$
\begin{aligned}
& \hat{\sigma}_{\varepsilon}^{2}=\hat{u^{\prime}}\left(I_{N} \otimes E_{T}\right) \hat{u} / N(T-1) \\
& \hat{\sigma}_{1}^{2}=\hat{u}\left(I_{N} \otimes \bar{J}_{T}\right) \hat{u} / N \\
& \bar{J}_{T}=J_{T} / T, E_{T}=I_{T}-\bar{J}_{T} .
\end{aligned}
$$

and $u$ are the maximum likelihood residuals under the null hypothesis. $J$ is an information matrix while

$\mathrm{G}$ is a bidiagonal matrix with bidiagonal elements all equal to one.

Test results for serial correlation are displayed in the third row of Table 2, along with the other panel model specification tests. They fail to reject the null hypothesis, indicating no serial correlation in the production functions for all five crops. Since the region production function errors are not time 
specific, the estimates in Table 3 are efficient and unbiased. Another assumption of the maximum

likelihood models are that the error terms are normally distributed. A standard test of this assumption is available in Greene (chapter 4) and the null hypothesis of non-normality is rejected with $99 \%$ confidence. Test statistics are reported in the last row of Table 2.

\section{Variability Results from the Estimated Model}

As was the case for the average production functions, the clearest results are obtained for corn, cotton and sorghum, and do not depend on functional form (Table 5). Increases in rainfall decrease the variability of corn and cotton yields. More precipitation also increases the variability of sorghum yields, which is not surprising given the tolerance of sorghum to dry conditions. Higher temperatures decrease the variance of cotton and sorghum yields, which is consistent with their geographic distribution.

Corn yields are predictably more variable with higher temperatures, because corn is grown in areas where it is seldom stressed by low temperatures. The deterministic trend in technology has an interesting positive impact on yield variability for these three crops. In Table 3 the deterministic trend has a positive impact on yield levels, so this might have been achieved at the expense of increased yield risk confirming work by Anderson and Hazell. More rainfall decreases the variability of wheat yields, but the temperature effect is mixed. For soybeans, the linearly estimated impacts are negative and the Cobb-Douglas estimates are positive.

Elasticities calculated for rainfall and temperature variability are reported in Table 6. Cotton and sorghum rainfall variability elasticities are all small, with a one percent increase in rainfall leading to a half of one percent or less increase or decrease in yield variability. Cotton and sorghum have high temperature variance elasticities with a one percent change in temperature leading to an up to eleven 
times decrease in yield variability. Similarly large elasticities are obtained for rainfall effects on corn and wheat yield variability. All of these results are consistent across functional forms. Soybean elasticities are all less than one, but sign inconsistency across functional forms make these results harder to interpret. The distinction between the impacts of climate on levels and variance of yields, raises several policy questions related to crop insurance and climate change assessment that will be addressed in the conclusions.

Finally and for perspective we used the regional estimates of climate change arising under the Canadian and Hadley simulators used under the US Global Climate Change Research Program's National Synthesis using the 2090 climate projections to obtain estimates of the effects of projected climate change on crop yield variance for selected crops in selected regions. These involved plugging the projected precipitation and temperature changes for the selected regions into the formulas and computing the projected yield changes into the Cobb Douglas form. The results are given in Table 7 and show uniform decreases in corn and cotton yield variability with mixed results for the other crops.

\section{Concluding Comments}

This study has developed quantitative estimates of the impacts of climate on yield variability of major U.S. agricultural crops by incorporating recent time series and panel data in Just-Pope stochastic production function estimation exercise. The results highlight crop specific differences in the climate impacts on yield levels and variability. For corn, precipitation and temperature results are found to have opposite effects on yield levels and variability. More rainfall causes corn yield levels to rise, while decreasing yield variance. Temperature has the reverse effects on corn yield levels and variance. 
For sorghum the effects go in the same direction, with higher temperatures reducing yields but also reducing variability. More rainfall increases sorghum yields but also increases variability.

These results have important policy implications. If future climate changes can be predicted to increase or decrease climate variables, a guide to possibly differential impacts on U.S. crops may be inferred from these results. This information might be useful to agricultural climate change impact modelers. These results could also be considered when future crop insurance programs are being constructed that protect farmers while providing desired incentives for adaptation through possible crop switching. Federal agricultural R\&D policy might also be informed by the results on deterministic technological advance. If further research continues to confirm the result that technology has improved yields while also intensifying cycles of boom and bust, it may be possible to formulate technological responses to the problem while relieving some of the burden on U.S. taxpayers evidenced by recent disaster relief packages. 
Table $1 \quad$ Unit Root Test Results

\begin{tabular}{|c|c|c|c|c|}
\hline $\begin{array}{l}\text { No-Serial } \\
\text { Correlation }\end{array}$ & Yield & Acre & Precipitation & Temperature \\
\hline Corn & $13.87^{*}$ & $65.08^{*}$ & $73.17 *$ & $125.88^{*}$ \\
\hline Cotton & $14.48^{*}$ & $35.38^{*}$ & $83.74 *$ & $81.18^{*}$ \\
\hline Sorghum & $14.83^{*}$ & $51.34 *$ & $91.02 *$ & $88.42^{*}$ \\
\hline Soybeans & $34.37 *$ & $52.39 *$ & $56.73^{*}$ & $104.00 *$ \\
\hline Wheat & $27.77 *$ & $46.82 *$ & $73.38^{*}$ & $128.81^{*}$ \\
\hline Serial correlation & Yield & Acre & Precipitation & Temperature \\
\hline Corn & $-4.86^{*}$ & $64.37 *$ & $63.88^{*}$ & $126.07 *$ \\
\hline Cotton & $6.86^{*}$ & $32.98 *$ & $67.63^{*}$ & $84.13^{*}$ \\
\hline Sorghum & $-2.26^{*}$ & $70.22 *$ & $81.82 *$ & $89.58^{*}$ \\
\hline Soybeans & $6.92 *$ & $63.06^{*}$ & $49.45^{*}$ & $101.26^{*}$ \\
\hline Wheat & $2.31^{*}$ & $50.88^{*}$ & $64.19^{*}$ & $126.20^{*}$ \\
\hline $\begin{array}{l}\text { Correlation across } \\
\text { groups }\end{array}$ & Yield & Acre & Precipitation & Temperature \\
\hline Corn & $2.79^{*}$ & $-3.72 *$ & $7.10^{*}$ & $9.92 *$ \\
\hline Cotton & $35.13^{*}$ & $-5.69 *$ & $\begin{array}{r}0.79 \\
28.22 *\end{array}$ & $1.91^{*}$ \\
\hline Sorghum & $\begin{array}{r}0.55 \\
10.40^{*}\end{array}$ & $-3.34 *$ & $2.54^{*}$ & $2.21^{*}$ \\
\hline Soybeans & $8.17 *$ & $-6.98 *$ & $5.53^{*}$ & $\begin{array}{r}-0.48 \\
499.13^{*}\end{array}$ \\
\hline Wheat & $8.15^{*}$ & $-7.02 *$ & $7.05^{*}$ & $10.36^{*}$ \\
\hline
\end{tabular}

Notes: Table 1 reports three versions of Im et al.'s LM-bar test statistic. "Serial correlation" statistics are robust to error term serial correlation, while "correlation across groups" statistics are robust to serial correlation in the cross-section dimension.

Key: $\quad *$ Null hypothesis of non-stationarity is rejected with $99 \%$ confidence. 
Table 2 Panel Model Specification Tests

\begin{tabular}{lrrrrr}
\hline & Corn & Cotton & Sorghum & Soybeans & Wheat \\
\hline $\begin{array}{l}\text { Fixed vs. Random } \\
\text { Effects }\end{array}$ & $15.37^{*}$ & $6.44^{*}$ & $7.52^{*}$ & $14.45^{*}$ & $12.06^{*}$ \\
\hline Serial Correlation & $0.87^{* *}$ & $0.81^{* *}$ & $1.22^{* *}$ & $1.23^{* *}$ & $0.18^{* *}$ \\
\hline Normality & $6.27 \mathrm{E}+12^{*}$ & $123.34^{*}$ & $4.16 \mathrm{E}+12^{*}$ & $2.34 \mathrm{E}+9^{*}$ & $2.86 \mathrm{E}+12^{*}$ \\
\hline
\end{tabular}

Key: $\quad *$ Null hypothesis is rejected with $99 \%$ confidence.

** Fails to reject the null hypothesis of no serial correlation with $99 \%$ confidence. 
Table 3 Average Crop Yield Production Function ( $\mathrm{f}(\mathrm{X}, \$)$ )-Comparison of Maximum Likelihood Linear and Cobb-Douglas Estimates

\begin{tabular}{|c|c|c|c|c|c|}
\hline Corn & Acre & Precipitation & Temperature & Year & Constant \\
\hline Linear & $\begin{array}{r}0.0146^{*} \\
(0.00039)\end{array}$ & $\begin{array}{r}0.9265^{*} \\
(0.00606)\end{array}$ & $\begin{array}{c}-0.3843^{*} \\
(0.01599)\end{array}$ & $\begin{array}{r}3.3018^{*} \\
(0.06492)\end{array}$ & $\begin{array}{r}0.4430 \\
(0.9978)\end{array}$ \\
\hline $\begin{array}{l}\text { Cobb- } \\
\text { Douglas }\end{array}$ & $\begin{array}{r}1.0728^{*} \\
(0.00105)\end{array}$ & $\begin{array}{r}1.5148^{*} \\
(0.00160)\end{array}$ & $\begin{array}{c}-2.9792 * \\
(0.00064)\end{array}$ & $\begin{array}{r}2.0470 * \\
(0.00061)\end{array}$ & $\begin{array}{r}0.0560^{*} \\
(0.00007)\end{array}$ \\
\hline \multicolumn{6}{|l|}{ Cotton } \\
\hline Linear & $\begin{array}{c}-0.00010 * \\
(0.000001)\end{array}$ & $\begin{array}{l}0.00679 * \\
(0.00010)\end{array}$ & $\begin{array}{r}-0.02731 * \\
(0.00035)\end{array}$ & $\begin{array}{l}0.02107 * \\
(0.00014)\end{array}$ & $\begin{array}{r}2.8990 * \\
(0.02524)\end{array}$ \\
\hline $\begin{array}{l}\text { Cobb- } \\
\text { Douglas }\end{array}$ & $\begin{array}{l}0.30879 * \\
(0.00736)\end{array}$ & $\begin{array}{l}0.40751 * \\
(0.01812)\end{array}$ & $\begin{array}{r}-0.74763^{*} \\
(0.02059)\end{array}$ & $\begin{array}{r}-0.31626^{*} \\
(0.01382)\end{array}$ & $\begin{array}{r}2.6774^{*} \\
(0.01618)\end{array}$ \\
\hline \multicolumn{6}{|l|}{ Sorghum } \\
\hline Linear & $\begin{array}{l}0.00042^{*} \\
(0.00002)\end{array}$ & $\begin{array}{l}0.05786^{*} \\
(0.00086)\end{array}$ & $\begin{array}{c}-0.02242^{*} \\
(0.00281)\end{array}$ & $\begin{array}{l}0.10573^{*} \\
(0.00186)\end{array}$ & $\begin{array}{c}-1.4303^{*} \\
(0.19234)\end{array}$ \\
\hline $\begin{array}{l}\text { Cobb- } \\
\text { Douglas }\end{array}$ & $\begin{array}{r}0.3895^{*} \\
(0.02159)\end{array}$ & $\begin{array}{r}1.8977^{*} \\
(0.03633)\end{array}$ & $\begin{array}{c}-2.6070^{*} \\
(0.04189)\end{array}$ & $\begin{array}{r}1.3758^{*} \\
(0.02864)\end{array}$ & $\begin{array}{r}0.2610^{*} \\
(0.01441)\end{array}$ \\
\hline \multicolumn{6}{|c|}{ Soybeans } \\
\hline Linear & $\begin{array}{r}0.00149 * \\
(0.000006)\end{array}$ & $\begin{array}{r}-0.16234^{*} \\
(0.00082)\end{array}$ & $\begin{array}{l}0.00386^{*} \\
(0.00037)\end{array}$ & $\begin{array}{l}0.34695 * \\
(0.00145)\end{array}$ & $\begin{array}{r}29.865^{*} \\
(0.04464)\end{array}$ \\
\hline $\begin{array}{l}\text { Cobb- } \\
\text { Douglas }\end{array}$ & $\begin{array}{r}0.1558^{*} \\
(0.00086)\end{array}$ & $\begin{array}{r}0.3640 * \\
(0.00267)\end{array}$ & $\begin{array}{r}0.0016 \\
(0.00149)\end{array}$ & $\begin{array}{r}0.2113^{*} \\
(0.00159)\end{array}$ & $\begin{array}{r}1.5992^{*} \\
(0.00351)\end{array}$ \\
\hline \multicolumn{6}{|l|}{ Wheat } \\
\hline Linear & $\begin{array}{r}0.00130 * \\
(0.000004)\end{array}$ & $\begin{array}{r}-0.15262^{*} \\
(0.00054)\end{array}$ & $\begin{array}{c}-0.33372 * \\
(0.00145)\end{array}$ & $\begin{array}{l}0.63271 * \\
(0.00094)\end{array}$ & $\begin{array}{r}60.371^{*} \\
(0.08986)\end{array}$ \\
\hline $\begin{array}{l}\text { Cobb- } \\
\text { Douglas }\end{array}$ & $\begin{array}{l}0.03485^{*} \\
(0.01337)\end{array}$ & $\begin{array}{r}1.4178^{*} \\
(0.03053)\end{array}$ & $\begin{array}{c}-0.37209 * \\
(0.00613)\end{array}$ & $\begin{array}{c}-0.23611 * \\
(0.01605)\end{array}$ & $\begin{array}{r}1.6014 * \\
(0.00364)\end{array}$ \\
\hline
\end{tabular}

Key: Numbers in parentheses are standard errors.

* Significant at $99 \%$ confidence level. 
Table 4 Elasticity of Average Crop Yield to a Change in Climate

\begin{tabular}{lcrrrrr}
\hline Production & \multicolumn{2}{c}{ Corn } & \multicolumn{2}{c}{ Cotton } & \multicolumn{2}{c}{ Sorghum } \\
Function Form & Precipitation & Temperature & Precipitation & Temperature & Precipitation Temperature \\
\hline Linear & 0.3273 & -0.2433 & 0.0371 & -1.5334 & 2.8844 & -2.0866 \\
Cobb-Douglas & 1.5148 & -2.9792 & 0.4075 & -0.7476 & 1.8977 & -2.6070 \\
\hline \multicolumn{4}{c}{ Soybeans } & \multicolumn{2}{c}{ Wheat } \\
& Precipitation & Temperature & Precipitation & Temperature \\
\hline Linear & -0.2068 & 0.0002 & -0.1309 & -0.5076 \\
Cobb-Douglas & 0.34640 & N.S. & 1.4178 & -0.3721 & \\
\hline
\end{tabular}

Note: Linear elasticities are coefficients in the Table 3 times average climate divided by average yield.

Key: N.S. not significant. 
Table 5 Crop Yield Variability $(\mathrm{h}(\mathrm{X}, \mathrm{N}))$-Comparison of Maximum Likelihood Linear and Cobb-Douglas Estimates

\begin{tabular}{|c|c|c|c|c|c|}
\hline Corn & Acre & Precipitation & Temperature & Year & Constant \\
\hline Linear & $\begin{array}{r}0.0005^{*} \\
(0.000002)\end{array}$ & $\begin{array}{l}-0.2720^{*} \\
(0.00070)\end{array}$ & $\begin{array}{r}0.1172^{*} \\
(0.00105)\end{array}$ & $\begin{array}{c}0.2052^{*} \\
(0.00217)\end{array}$ & $\begin{array}{l}9.4197 * \\
(0.0555)\end{array}$ \\
\hline $\begin{array}{l}\text { Cobb- } \\
\text { Douglas }\end{array}$ & $\begin{array}{r}0.4711^{*} \\
(0.00116)\end{array}$ & $\begin{array}{l}-1.4461^{*} \\
(0.00284)\end{array}$ & $\begin{array}{r}0.8923^{*} \\
(0.11526)\end{array}$ & $\begin{array}{r}0.1356^{*} \\
(0.00019)\end{array}$ & $\begin{array}{l}2.2785^{*} \\
(0.4744)\end{array}$ \\
\hline \multicolumn{6}{|l|}{ Cotton } \\
\hline Linear & $\begin{array}{c}-0.00007^{*} \\
(0.000005)\end{array}$ & $\begin{array}{c}-0.04405^{*} \\
(0.00068)\end{array}$ & $\begin{array}{c}-0.15506^{*} \\
(0.00095)\end{array}$ & $\begin{array}{l}0.03161^{*} \\
(0.00052)\end{array}$ & $\begin{array}{r}9.2579 * \\
(0.06642)\end{array}$ \\
\hline $\begin{array}{l}\text { Cobb- } \\
\text { Douglas }\end{array}$ & $\begin{array}{r}0.2537^{*} \\
(0.00534)\end{array}$ & $\begin{array}{r}-0.02124 * \\
(0.00798)\end{array}$ & $\begin{array}{l}-3.5800^{*} \\
(0.22972)\end{array}$ & $\begin{array}{l}0.34964^{*} \\
(0.00798)\end{array}$ & $\begin{array}{l}13.519^{*} \\
(0.9732)\end{array}$ \\
\hline \multicolumn{6}{|l|}{ Sorghum } \\
\hline Linear & $\begin{array}{l}0.00028^{*} \\
(0.00003)\end{array}$ & $\begin{array}{l}0.01431^{*} \\
(0.00015)\end{array}$ & $\begin{array}{r}-0.07847 * \\
(0.00041)\end{array}$ & $\begin{array}{l}0.03925^{*} \\
(0.00030)\end{array}$ & $\begin{array}{l}8.7116^{*} \\
(0.0291)\end{array}$ \\
\hline $\begin{array}{l}\text { Cobb- } \\
\text { Douglas }\end{array}$ & $\begin{array}{c}0.2373^{*} \\
(0.00672)\end{array}$ & $\begin{array}{l}0.48029^{*} \\
(0.00399)\end{array}$ & $\begin{array}{c}-2.5633^{*} \\
(0.05870)\end{array}$ & $\begin{array}{l}0.55248^{*} \\
(0.00269)\end{array}$ & $\begin{array}{l}11.238^{*} \\
(0.2211)\end{array}$ \\
\hline \multicolumn{6}{|c|}{ Soybeans } \\
\hline Linear & $\begin{array}{c}-0.00006^{*} \\
(0.000001)\end{array}$ & $\begin{array}{c}-0.02048^{*} \\
(0.00021)\end{array}$ & $\begin{array}{c}-0.16895^{*} \\
(0.00139)\end{array}$ & $\begin{array}{c}-0.00148^{*} \\
(0.00033)\end{array}$ & $\begin{array}{r}5.0756 * \\
(0.01035)\end{array}$ \\
\hline $\begin{array}{l}\text { Cobb- } \\
\text { Douglas }\end{array}$ & $\begin{array}{c}0.0210^{*} \\
(0.00356)\end{array}$ & $\begin{array}{c}0.8194 * \\
(0.02242)\end{array}$ & $\begin{array}{c}0.0586^{*} \\
(0.00267)\end{array}$ & $\begin{array}{r}0.2028^{*} \\
(0.00846)\end{array}$ & $\begin{array}{l}0.4920^{*} \\
(0.0803)\end{array}$ \\
\hline \multicolumn{6}{|l|}{ Wheat } \\
\hline Linear & $\begin{array}{c}-0.00003^{*} \\
(0.000001)\end{array}$ & $\begin{array}{c}-0.06201 * \\
(0.00006)\end{array}$ & $\begin{array}{r}-0.00167 * \\
(0.00015)\end{array}$ & $\begin{array}{l}0.05412^{*} \\
(0.00015)\end{array}$ & $\begin{array}{r}6.4186^{*} \\
(0.01034)\end{array}$ \\
\hline $\begin{array}{l}\text { Cobb- } \\
\text { Douglas }\end{array}$ & $\begin{array}{l}0.14732 * \\
(0.01035)\end{array}$ & $\begin{array}{c}-1.6473 * \\
(0.01493)\end{array}$ & $\begin{array}{r}5.0875^{*} \\
(0.24809)\end{array}$ & $\begin{array}{c}-2.1145^{*} \\
(0.02403)\end{array}$ & $\begin{array}{r}-8.8744^{*} \\
(0.9673)\end{array}$ \\
\hline
\end{tabular}

Key: Numbers in parentheses are standard errors.

* Significant at $99 \%$ confidence level. 
Table 6 Elasticity of Variance in Crop Yield to a Change in Climate

\begin{tabular}{|c|c|c|c|c|c|c|}
\hline \multirow{2}{*}{$\begin{array}{l}\text { Yield Variability } \\
\text { Function } \\
\text { Linear }\end{array}$} & \multicolumn{2}{|c|}{$\begin{array}{c}\text { Corn } \\
\text { Precipitation Temperature }\end{array}$} & \multicolumn{2}{|c|}{$\begin{array}{c}\text { Cotton } \\
\text { Precipitation Temperature }\end{array}$} & \multicolumn{2}{|c|}{$\begin{array}{c}\text { Sorghum } \\
\text { Precipitation Temperature }\end{array}$} \\
\hline & -9.7187 & 7.5058 & -0.3028 & -10.9386 & 0.5230 & -5.3517 \\
\hline \multirow[t]{3}{*}{ Cobb-Douglas } & -1.4461 & 0.8923 & -0.0212 & -3.5800 & 0.4802 & -2.5633 \\
\hline & \multicolumn{2}{|c|}{ Soybeans } & \multicolumn{2}{|c|}{ Wheat } & & \\
\hline & Precipitation & Temperature & Precipitation & Temperature & & \\
\hline Linear & -0.7932 & -0.2739 & -2.1572 & -0.1035 & & \\
\hline Cobb-Douglas & 0.8194 & 0.0586 & -1.6473 & 5.0875 & & \\
\hline
\end{tabular}


Table 7. Percentage Increase in Crop Variability for 2090 Year by Scenario

\begin{tabular}{|c|c|c|c|c|c|c|c|c|c|c|}
\hline & \multicolumn{5}{|c|}{ Canadian Climate Change Scenario } & \multicolumn{5}{|c|}{ Hadley Climate Change Scenario } \\
\hline & Corn & $\begin{array}{c}\text { Soybean } \\
\text { s }\end{array}$ & Cotton & Wheat & Sorghum & Corn & $\begin{array}{c}\text { Soybean } \\
\text { s }\end{array}$ & Cotton & Wheat & $\begin{array}{l}\text { Sorghu } \\
\mathrm{m}\end{array}$ \\
\hline $\mathrm{CA}$ & & & -12.84 & & & & & -11.81 & & \\
\hline $\mathrm{CO}$ & & & & 34.43 & & & & & -10.60 & \\
\hline GA & & & -10.35 & & & & & -6.92 & & \\
\hline IL & -25.71 & 21.28 & & & & -24.73 & 18.90 & & & \\
\hline IN & -8.73 & 8.06 & & & & -26.31 & 20.30 & & & \\
\hline IA & -36.89 & 33.14 & & & & -26.83 & 20.90 & & & \\
\hline KS & & & & -14.39 & -0.75 & & & & -18.16 & 3.38 \\
\hline LA & & & -13.03 & & & & & -7.97 & & \\
\hline MN & & 4.01 & & & & & 10.60 & & & \\
\hline MT & & & & 32.86 & & & & & -6.36 & \\
\hline MS & & & -13.92 & & & & & -7.73 & & \\
\hline $\mathrm{NE}$ & 15.30 & -4.74 & & 48.22 & -16.15 & -15.05 & 11.65 & & -5.57 & -1.72 \\
\hline OK & & & & 16.34 & -9.27 & & & & -17.07 & 2.83 \\
\hline SD & -21.75 & & & -6.94 & & -24.37 & & & -19.10 & \\
\hline TX & & & -13.21 & 27.86 & -10.83 & & & -8.05 & 2.26 & -3.10 \\
\hline
\end{tabular}




\section{References}

Adams, R.M., B.H. Hurd, S. Lenhart, and N. Leary . "Effects of Global Climate Change on Agriculture: An Interpretative Review", Climatic Research 11(1998):19-30.

Anderson, J. R. "Sparse Data, Climatic Variability, and Yield Uncertainty in Response Analysis." American Journal of Agricultural Economics 55(1973):77-82.

Anderson, J. R. and P.B.R. Hazell. Variability in Grain Yields: Implications for Agricultural Research and Policy in Developing Countries, 1987, Baltimore and London, Published for the International Food Policy Research Institute, The Johns Hopkins University Press.

Antle, J.M. "Econometric Estimation of Producers' Risk Attitudes." American Journal of Agricultural Economics 69(1987):509-522.

Baltagi, B.H. Econometric Analysis of Panel Data, 1995, John Wiley \& Sons published.

Baltagi, B. H. and Q. Li. "Testing AR(1) Against MA(1) Disturbances in an Error Component Model." Journal of Econometrics, 1995, 68(1):133-51.

Banerjee, A., J. Dolado, J.W. Galbraith, and D.F. Hendry, Co-integration, Error Correction, and the Econometric Analysis of Non-stationary Data, 1993, Oxford University Press Inc., New York, NY.

Breusch, T.S. and A.R. Pagan. "The Lagrange Multiplier Test and its Applications to Model Specification in Econometrics." Review of Economic Studies 1980, 47:239-253.

Buccola, S.T. and B.A. McCarl. "Small-sample Evaluation of Mean-variance Production Function Estimators." American Journal of Agricultural Economics. 68(1986):732-738.

Cane, M.A., G. Eshel, and R.W. Buckland. "Forecasting Zimbabwean Maize Yield Using Eastern Equatorial Pacific Sea Surface Temperature" Nature 370(1994):204-205

Coakley, J. and A.M. Fuertes, “New Panel Unit Root Tests of PPP.” Economics Letters 1997(57), P17-22.

Dickey, D. and W. Fuller. "Likelihood Ratio Statistics for Autoregressive Time Series with a Unit Root.” Econometrica, 49(1981), P1057-72.

Downton, M.W. and K.A. Miller. "The Freeze Risk to Florida Citrus. Part II: Temperature Variability and Circulation Patterns." Journal of Climate 6(1993):364-372. 
Granger, C.W.J. and P. Newbold, "Spurious Regressions in Economics." Journal of Econometrics 2(1974), 111-120.

Hausman, J. A. "Specification Tests in Econometrics." Econometrica 1978, 46(6):1251-1271.

Hazell, P.B.R. "Sources of Increased Instability in Indian and U.S. Cereal Production." American Journal of Agricultural Economics 66(1984), 302-11.

Heimonen, K. "Stationarity of the European Real Exchange Rates-- Evidence from Panel Data." Applied Economics, 31(1999), 673-677.

Honda, Y. "Testing the Error Components Model with the Non-Normal Disturbances.", Review of Economic Studies, 52(1985), 681-690.

Im, K.S., M.H.Pesaran, Y. Shin, “Testing for Unit Roots in Heterogenous Panels.” Working Paper 9526, Department of Applied Economics, University of Cambridge. Dec. 1997.

Just, R. and R.D. Pope, "Stochastic Specification of Production Function and Economic Implications." Journal of Econometrics 7(1978), 67-86.

Just, R. and R.D. Pope, "Production Function Estimation and Related Risk Considerations." American Journal of Agricultural Economics 61(1979), 277-84.

Levin, A. and C.F. Lin, "Unit Root Tests in Panel Data: Asymptotic and Finite-Sample Properties." unpublished manuscript, University of California, San Diego, June, 1992.

Levin, A. and C.F. Lin, "Unit Root Tests in Panel Data: New Results.” Discussion Paper 93-56, University of California, San Diego, 1993.

Lewandrowski, J., and D.E. Schimmelpfennig. "Economic Implications of Climate Change for U.S. Agriculture: Assessing Recent Evidence.” Land Economics 75(1999):39-57.

Love, H.A. and S.T. Buccola. "Joint Risk Preference-Technology Estimation with a Primal System." American Journal of Agricultural Economics. 73(1991):765-774.

McCarl, B.A. and R.B. Rettig. "Influence of Hatchery Smolt Releases on Adult Salmon Production and Its Variability. Canadian Journal of Fisheries and Aquatic Sciences. 11(1983):18801886.

Mearns, L.O. C. Rosenzweig, and R. Goldberg. "The Effect of Changes in Daily and Interannual 
Climatic Variability on Ceres-Wheat: A Sensitivity Study.” Climatic Change 32(1996):257292.

Mearns, L.O., C. Rosenzweig, and R. Goldberg. "Mean and Variance Change in Climate Scenarios: Methods, Agricultural Applications, and Measures of Uncertainty." Climatic Change 35(1997):367-396.

Mendelsohn, R., W.D. Nordhaus, and D. Shaw. "The Impact of Global Warming on Agriculture: A Ricardian Analysis." American Economic Review 84(1994):753-71.

NOAA home-page http://ftp.ncdc.noaa.gov/pub/ushen/ 1999.

Phillips, P.C.B. "Understanding Spurious Regressions in Econometrics" Journal of Econometrics 33(1986):311-40.

Quah, D. "Exploiting Cross-Section Variation for Unit Root Inference in Dynamic Data." Economics Letters, 44(1994), P9-19.

Roumasset, J., M.Rosegrant, U. Chakravorty, and J. Anderson, "Fertilizer and Crop Yield Variability: A Review." P223-233, Variability in Grain Yields: Implications for Agricultural Research and Policy in Developing Countries, 1987, Baltimore and London, Published for the International Food Policy Research Institute, The Johns Hopkins University Press.

Saha, A., A. Havenner, H. Talpaz. "Stochastic Production Function Estimation: Small Sample Properties of ML versus FGLS." Applied Economics 29(1997):459-69.

Saha, A., C.R. Shumway, and H. Talpaz. "Joint Estimation of Risk Preference Structure and Technology Using Expo-Power Utility." American Journal of Agricultural Economics 76(1994):173-84.

Schimmelpfennig, D.E. "Uncertainty in Economic Models of Climate Change Impacts." Climatic Change 33(1996):213-234.

Schimmelpfennig, D.E. and G. Yohe. "Vulnerability of Agricultural Crops to Climate Change: A Practical Method of Indexing," Global Environmental Change and Agriculture: Assessing the Impacts, G. Frisvold and B. Kuhn, eds. Northampton, MA: Edward Elgar Publishing Limited, pp.193-217, 1999.

Tollini, H. and J.A. Seagraves "Actual and Optimal Use of Fertilizer: The Case of Nitrogen on Corn in Eastern North Carolina." Economic Research Report, Department of Economics, North Carolina State University at Raleigh, 1970. 
USDA-NASS Agricultural Statistics 1999, http://www.usda.gov/nass/pubs/agr99/acro99.htm 